\title{
Creativity among the Students of Jawahar Navodaya Vidyalayas and Kendriya Vidyalayas
}

\author{
Kiran NC ${ }^{1 *}$, C. G. Venkatesha Murthy ${ }^{2}$
}

\section{ABSTRACT}

In the present study, the researchers have attempted to assess the Creativity among 770 students of JNV and KV comprising 320 from JNVs and 450 from KVs. There was a significant difference between the students of JNV's and KV's on Creativity in favour on JNV' students. While boys and girls of JNV's did not differ on Creativity. Among the students of KVs, the boys and girls differed significantly on creativity in favour of boys. Finally, there was no significant difference between the boys and girls of JNV's and KV's put together on Creativity. The implications of nurturing creativity among students are discussed.

Keywords: Creativity, Students, Jawahar Navodaya Vidyalayas, Kendriya Vidyalayas

Jawahar Navodaya Vidyalayas and Kendriya Vidyalayas are managed by the Government of India. The former is a residential school set up, while the latter is a non-residential set us. The Navodaya Vidyalaya Scheme was started during the year 1985-86 and is managed by Navodaya Vidyalaya Samiti which is fully financed by the Government of India. These schools were started to identify and nurture the rural talent of the country. While, the Kendriya Vidyalayas aim is to cater to the educational needs of the children of Central Government Employees, which predominantly is located in urban centers.

There are 596 Navodaya Vidyalayas all over the country, while there are 978 Kendriya Vidyalayas in the country. The admission process for JNV is through a selection test at the district level, where only 80 students are selected for class VI. While, in Kendriya Vidyalaya students are given admission only to the children of Central Government employees. Students get selected based on computerized lottery system. Getting admission to either JNV or KV is a matter of prestige for children as it is generally considered by the public. They both are affiliated to CBSE. The teachers of both the schools are selected rigorously and they are transferable

\footnotetext{
${ }^{1}$ Research Scholar, Regional Institute of Education (NCERT) Mysore, India

${ }^{2}$ Professor, Regional Institute of Education (NCERT) Mysore, India

*Responding Author

Received: March 8, 2017; Revision Received: March 26, 2017; Accepted: March 29, 2017

(C) 2017 Kiran NC, Murthy V; licensee IJIP. This is an Open Access Research distributed under the terms of the Creative Commons Attribution License (www.creativecommons.org/licenses/by/2.0), which permits unrestricted use, distribution, and reproduction in any Medium, provided the original work is properly cited.
} 


\section{Creativity among the Students of Jawahar Navodaya Vidyalayas and Kendriya Vidyalayas}

throughout the country. The teacher training programmes are also given importance and they both get quality facilities and they are paid as per the norms of the Government of India. Since JNVs and KVs have the best teachers, it is worthwhile studying their influence on the manifestation of creative potential among their students.

\section{REVIEW OF LITERATURE}

Creative people are characterized by being unconventional, individualistic, inventive, driven, visionary, intuitive, curios, fluent, uninhibited, risk taking, imaginative, humorous, sensitive, non-conformity, inquisitive, constructive-discontent, and those who have the ability to suspend judgment and criticism, perseverance and flexible in imagination (George, 2005). According to Guilford (1966, p.13) "Creativity is the key to education in its fullest sense and to the solution of mankind's most serious problems." This adequately advocates the need for nurturing creative potentials among school children. According to Parnes, (1963). "Creativity is thinking and responding process that involves connecting with our previous experience, responding to stimuli (objects, symbols, ideas, people, and situations) and generally to at least one unique combination." Educators and researchers believe that it's important to teach and foster creativity inside the classroom unit. Paradoxically, researchers have found that the school climate and curriculum guidelines discourage creativity (Andilou \& Murphy, 2010; Baer \& Kaufman, 2012; Benavides, Dumont, \& Istance, 2008).

'Traditionally, the more the student's answer conforms to one or more predetermined responses, the higher the grade. Thus, in many assessment programs, a culture that rewards uncreative thinking is cultivated, rather than a culture that encourages and rewards creative answers' (Plucker, \& Makel, 2010; \& Runco, 2010).

In order to be creative one must first learn to generate new ideas, analyze these ideas, and share the ideas with others. A person may have the creative skills but may not apply them to situations that require solving a complex problem which involves creativity. 'In order to encourage the decision to be creative, one should believe that he or she will be awarded for the attempt to be more creative rather than punished '(O’Hara \& Sternberg, 2001, pp.197-210). Therefore, in order to promote creativity there is a need in schools to construct opportunities for students to engage in it, encourage, and reward them to respond to novel ideas.

Researchers are curious in understanding the role of creativity in education. Creativity has been found to be significantly related to academic achievement by Russ et al., (2003). 'Creativity contributes towards the mental health, education, vocational success and many other important areas in life. School environment is an important determinant of the creativity of students' (Sarah, 2013). Further, the role of teachers in developing creativity has also been studied and found that it plays a very important role in providing a conducive climate for creative growth in the classroom (Roy 2008). 


\section{METHODOLOGY}

In the present study, the researchers have raised the following research questions and also answered through the present study.

\section{Research Question}

1. Do students of JNV's and KV's differ on Creativity?

2. Do boys and girls of JNV's differ significantly on Creativity?

3. Do boys and girls of KV's differ significantly on Creativity?

4. Do boys and Girls differ significantly on creativity?

In order to answer the above research questions the following objectives have been developed and achieved in the present study.

\section{Objectives}

1. To study whether students of JNV's and KV's differ significantly on Creativity.

2. To study whether boys and girls of JNV's differ significantly on Creativity.

3. To study whether boys and girls of KV's differ significantly on Creativity.

4. To study whether boys and Girls differ significantly on creativity.

In order to achieve the above objectives, the following hypothesis have been generated and tested in the study.

\section{Hypotheses}

H1: There is no significant difference between the students of JNV's and KV's on Creativity.

H2: There is no significant difference between the boys and girls of JNVs on Creativity.

H3: There is no significant difference between the boys and the girls of KVs on Creativity.

H4: Boys and Girls do not differ significantly on Creativity.

\section{Design of the Study}

The present study is a descriptive survey aiming at finding out whether students of JNVs and KVs differ on Creativity.

\section{Sample}

The sample of the study covered 770 students, comprising boys and girls studying in $8^{\text {th }}$ standard of Navodaya Vidyalayas and Kendriya Vidyalayas in Karnataka selected using stratified random sampling technique. 
Creativity among the Students of Jawahar Navodaya Vidyalayas and Kendriya Vidyalayas

Sampling Framework

\begin{tabular}{|c|c|c|c|c|}
\hline \multicolumn{5}{|c|}{ JNV and KV students of $8^{\text {th }}$ Standard } \\
\hline & \multicolumn{2}{|c|}{ KV's Schools - 9} & \multicolumn{2}{|c|}{ JNV's Schools - 8} \\
\hline & North Karnataka & South Karnataka & North Karnataka & South Karnataka \\
\hline Schools & 4 & 5 & 5 & 3 \\
\hline \multirow[t]{2}{*}{ Students } & 200 & 250 & 200 & 120 \\
\hline & \multicolumn{2}{|c|}{450} & \multicolumn{2}{|c|}{320} \\
\hline Total & & & & \\
\hline
\end{tabular}

Tools and Techniques

\begin{tabular}{|l|l|l|}
\hline \multicolumn{1}{|c|}{ Variables } & \multicolumn{1}{c|}{ Tool } & \multicolumn{1}{c|}{ Author } \\
\hline Creativity & Verbal Test of Creativity & Baqer Mehdi(2009) \\
\hline Personal Data Sheet & Developed by the Researchers & \\
\hline
\end{tabular}

Following tools were used in the study.

\section{Data collection Procedure}

The selected students of the sample were administered the Verbal Test of Creativity and the personal data from the Jawahar Navodaya Vidyalayas and Kendriya Vidyalayas following the protocol, in Karnataka.

\section{RESULTS \& DISCUSSION}

The collected data were scored, tabulated and their descriptive statistics were calculated. Further, hypothesis wise the results were treated with inferential statistics. The obtained results are presented and discussed hypothesis-wise as follows.

Hypothesis 1. There is no significant difference between the students of JNV's and KV' on Creativity.

In order to test the above hypothesis the mean scores obtained by the students of JNV and KV on Creativity test was computed apart from the computation of SD and SE. Further, the significance of the difference between the means scores of the two schools was also computed using " $t$ " test which yielded the following.

Table 1. Significance of the difference between the students of JNV and KV on Creativity

\begin{tabular}{|c|c|c|c|c|c|c|c|c|}
\hline \multicolumn{9}{|c|}{ Independent sample test } \\
\hline Schools & $\mathbf{N}$ & Mean & SD & SE & df & t-value & Sig. & Inference \\
\hline $\mathrm{KV}$ & 450 & 47.67 & 9.14 & .43 & & & & \\
\hline JNV & 320 & 50.65 & 10.38 & .58 & 768 & 4.20 & .000 & Significant \\
\hline
\end{tabular}

An analysis of the above table indicates that there were 450 students of KVs and 320 students of JNVs. The mean score of the students of KVs is 47.67, while that of JNVs is 50.65. Apparently, students of JNVs have an edge over the KV students. While, in terms of the standard deviation,

(C) The International Journal of Indian Psychology, ISSN 2348-5396 (e) | ISSN: 2349-3429 (p) | 163 


\section{Creativity among the Students of Jawahar Navodaya Vidyalayas and Kendriya Vidyalayas}

KVs have 9.14, while that of JNVs have 10.38. It means, the spread of scores away from the mean is apparently more among JNV students suggesting that the variation is more among the JNV students as compared to the students of KVs. In order to see whether the obtained mean difference is true of the population also, the scores were subjected to " $t$ " test, which was 4.20 , which is statistically significant at 0.01 levels. This statistically significant difference is in favor of JNV Students. Therefore, the null hypothesis is rejected. It means the students of JNV s and KVs have differed significantly on creativity in favor of JNV students as their mean scores are higher than the students of KVs. It means the students of JNVs are significantly more creative than the students of KVs. This could be because, the students selected for the JNVs are selected at the district level and are provided education in a residential set up, while it is not so with KV students. As JNVs are opened with the objective of identifying the rural talents and to nurture them, perhaps the present study is validating the expectations of opening the JNVs. Sehgal, (1978) found that the students of residential model schools were more creative than those of government and private schools. Similar findings were recorded by Sultana, (1980), Haddon \& Lytton (1968), Ezekeil (1966) Rastogi (1967) and Chatterjee, (1970). Therefore, the above finding that the students of JNVs are significantly more creative than the students of KVs has support from other studies too. It could be because the students and teachers are both available on the campus for the entire day and their opportunities of interaction and influence will be for a longer period than the students and teachers of the non residential schools. In a study, Renuka (2003) found that the Gurukul, a residential school students significantly differed from Govt. non residential school on Elaboration, but not on the other three dimensions of creativity i.e., fluency, flexibility, and elaboration. So partially, the above finding is corroborated by this study.

Agarwal, (1992) studied students of Kendriya Vidyalayas and found them to be significantly better than other management schools on creativity covering students of public, government (managed by state government) and aided residential schools (grant maintained) . The type of educational administration in a school is a significant factor in the development of creativity. The efforts of Kendriya Vidyalayas get due rewards in the form of the growth of creative potential of their students.

\section{Hypothesis 2. There is no significant difference between the boys and girls of JNVs on Creativity.}

In order to test the above hypothesis the mean scores obtained by the boys and girls of JNV's on Creativity test was computed apart from the computation of SD and SE. Further, the significance of the difference between means scores of the two groups were computed using " $t$ " test which yielded the following. 
Creativity among the Students of Jawahar Navodaya Vidyalayas and Kendriya Vidyalayas

Table 2. Significance of the difference between the boys and girls of JNVs on Creativity

\begin{tabular}{|l|l|l|l|l|l|l|l|l|}
\hline \multicolumn{10}{|c|}{ Independent sample test } \\
\cline { 1 - 5 } & & Mean & SD & SE & df & t-value & Sig. & \multicolumn{1}{|c|}{ Inference } \\
\hline Boys & 176 & 50.51 & 10.51 & .79 & & & & $\begin{array}{l}\text { Not } \\
\text { Significant }\end{array}$ \\
\hline
\end{tabular}

An analysis of the above table indicates that among the JNV school students, there were 176 boys and 144 girls taking the total to 320 students. In terms of their mean scores, the boys have scored 50.51 while the girls have scored 50.82 indicating a small difference, apparently in favor of girls. In terms of the SD the boys have 10.51 while the girls have 10.25 suggesting very little difference. In order to see whether the obtained mean difference is statistically significant, they were subjected to " $t$ " test and found that two groups of boys and girls have not been found to differ significantly. So the null hypothesis is accepted. It means the boys and the girls of JNVs are alike on their creativity and they do not differ. This further validates that the selection of students to JNVs has not found any variation in terms of the creative powers of boys and girls. Torrance (1983) wrote, "A substantial body of evidence indicates that males and females perform at similar levels of tests designed to measure creative potential" (p.134). There are studies which highlight no statistically significant sex differences on the dimensions of verbal creativity by Phatak (1962), Tharnmaprateep (1976), and Rasool (1977). In fluency (Badrinath \& Satyanaryana, (1979) or the flexibility dimensions (Sharma 2015; Vohra, 1975; Singh, 1993, pp.114-116). The present research finding goes with these studies.

\section{Hypothesis 3. There is no significant difference between the boys and the girls of KVs on Creativity.}

In order to test the above hypothesis the mean scores obtained by the boys and girls of KVs on Creativity test was computed apart from the computation of SD and SE. Further, the significance of the difference between means scores of the two groups were computed using " $t$ " test which yielded the following.

Table 3. Significance of the difference between the boys and girls of KVs on Creativity

\begin{tabular}{|c|c|c|c|c|c|c|c|c|}
\hline \multicolumn{10}{|c|}{ Independent sample test } \\
\cline { 1 - 6 } & & Mean & SD & SE & df & t-value & Sig. & Inference \\
\hline Boys & 226 & 48.34 & 10.15 & .67 & & & & \\
Girls & 224 & 47.00 & 7.96 & .53 & 448 & 1.559 & .02 & Significant \\
\hline
\end{tabular}

An analysis of the above table indicates that there are 226 boys and 224 girls in the KVs taking the total to 450 students, who are a part of the study. The mean scores of the boys on creativity test is 48.34 and that of girls is 47.00 . There is a marginal apparent difference of mean scores in favor of boys. In terms of the standard deviation, the boys have 10.15, while the girls have 7.96, suggesting that the scores of boys are spread more away from the mean scores than that of the of the girls. In order to test the obtained mean difference for their statistical significance, the scores

(c) The International Journal of Indian Psychology, ISSN 2348-5396 (e)| ISSN: 2349-3429 (p) | 165 


\section{Creativity among the Students of Jawahar Navodaya Vidyalayas and Kendriya Vidyalayas}

were subjected to $t$ test and found to be 1.55 , which is significant at 0.05 levels. So the null hypothesis is rejected. It means, the boys and girls of KVs differ significantly on creativity in favor of boys. The boys of the KVs are significantly more creative than their girl counterparts. This difference could be incidental as no specific explanation could be offered other than the one that the KVs have admitted students and provided education to students among whom boys are better than girls on their creativity.

Studies revealed by Torrance $(1962,1965)$ and Harold's (1968) results indicated that there is significant sex differences on several creativity variables, with males being stronger than the females. Raina, (1969) also found that boys excelled on all the figural measures of creative thinking as well as some of the verbal measures. Nayana, (1981) found that males excelled females on measures of verbal flexibility, figural originality and figural elaboration. Singh, (1982) found that boys to achieve significantly higher mean scores than the girls on the measure of creative thinking. Lau \& $\mathrm{Li}$ (1996) found boys to be more creative than girls as (cited in Saima, 2011, p.6). On the reverse direction, there are studies which have found that girls are significantly higher on creativity than boys. It includes, Richmond (1971), Flaherty (1992), Kogan (1974), Tegano and Moran (1989), Coone (1969), and Warren \& Luria (1972). Therefore, there are studies which have established the sex differences on creativity. However, it is not unidirectional when the gender and creativity are studied. But the present study has found that the boys have significantly bettered girls on creativity among the students of KVs.

\section{Hypothesis 4. Boys and Girls do not differ significantly on Creativity.}

In order to test the above hypothesis the mean scores obtained by the boys and girls on Creativity test was computed apart from the computation of SD and SE. Further, the significance of the difference between means scores of the two groups were computed using " $t$ " test which yielded the following.

Table 4. Significance of the difference between the boys and girls on Creativity

\begin{tabular}{|c|c|c|c|c|c|c|c|c|}
\hline \multicolumn{9}{|c|}{ Independent sample test } \\
\hline \multicolumn{2}{|c|}{} & Mean & SD & SE & df & t-value & Sig. & Inference \\
\hline Boys & 402 & 49.29 & 10.35 & .51 & & & & Not \\
Girls & 368 & 48.50 & 9.11 & .47 & 768 & 1.12 & .06 & Significant \\
\hline
\end{tabular}

An analysis of the above table indicates in total there are 402 boys and 368 girls taking the total to 770 in the study. In terms of the mean scores, the boys have 49.29 while the girls have 48.50 , which leave a small difference apparently in favor the boys. On the issue of the standard deviation, the boys have 10.35, while the girls have 9.11 suggesting that the spread of scores away from the mean is more among the boys in comparison to the girls. The obtained " $t$ " value is 1.12 , which is not statistically significant. So the null hypothesis is accepted. It means, the boys and girls irrespective of whether they belong to JNVs or KVs do not differ on creativity and

(c) The International Journal of Indian Psychology, ISSN 2348-5396 (e)| ISSN: 2349-3429 (p) | 166 


\section{Creativity among the Students of Jawahar Navodaya Vidyalayas and Kendriya Vidyalayas}

they are the same. It goes to say that gender has no role to play when students of JNVs and KVs are taken together. The studies presented for hypothesis 2 holds good here too.

\section{CONCLUSIONS}

1. The students of JNV's are more creative than the students of KV's.

2. The boys and girls of JNV's do not differ on Creativity.

3. The boys of KVs are more creative their girl counterparts. So by implication, JNV girls are better than KV girls on creativity.

4. The boys and girls of JNV's and KV's put together, are alike on their Creativity.

\section{Implications}

Creativity is a great asset and a virtue among children which needs to be assessed and nurtured by schools and community. Teachers in schools are to be aware of these potentialities and work towards nurturing the same. Since the students of JNVs are found to be more creative and within them boys and girls do not differ, it indicates that the JNVs are in a position where the boys and girls are alike and they need to be nurtured further. While among the students of KVs, boys have an edge over girls on creativity, and on the whole they are less creative than JNV students. The $\mathrm{KV}$ teachers need to understand these variations and work towards enhancing differing levels of creativity among their students. In either case, the role of a teacher becomes seminal in understanding the creative potentials of their students and nurtures them. It is desirable that the takeaways of these studies reach the attention of teachers in the interest of their students.

\section{Acknowledgments}

The author appreciates all those who participated in the study and helped to facilitate the research process.

Conflict of Interests: The author declared no conflict of interests.

\section{REFERENCES}

Agarwal, K. P. (1992). Development of Creativity in Indian Schools some related issues. New Delhi: Concept Published Company, pp.18-19.

Andiliou, A. \& Murphy, P. K. (2010). Examining variations among researchers' and teachers’ conceptualizations of creativity: A review and synthesis of contemporary research. Educational Research Review, 5, 201-219.

Badrinath, S., \& Satyanarayana, S. B. (1979). Correlates of creative thinking of high school students. Creativity Newsletter, Vol. 7 \& 8, No.2 \& 1.

Baer, J., \& Kaufman, J. C. (2008). Gender differences in creativity. Journal of Creative Behavior, 42, (2), 75-105.

Benavides, F., Dumont, H., \& Istance, D. (2008). The search for innovative learning environments. In OECD (Ed.), Innovating to learn, learning to innovate,pp. 21-44.

(c) The International Journal of Indian Psychology, ISSN 2348-5396 (e)| ISSN: 2349-3429 (p) | 167 


\section{Creativity among the Students of Jawahar Navodaya Vidyalayas and Kendriya Vidyalayas}

Chatterjee, B. B. (1970). Explanation of Some Structural Components of Creativity through Projective Tests, Varanasi: Gandhian Institute of Studies.

Coone, J.G. (1969). A Cross Cultural Study of sex differences in the development of selected creative thinking abilities. Dissertation Abstracts International, 29, 4828.

Ezekeil, (1966, cited in Agarwal, K. P., 1992). Development of creativity in Indian schools: Some related issues. New Delhi: Concept Published Company, pp. 43-44.

Flaherty, M.A. (1992). The effects of holistic creativity programmes on the self concept and creativity of third graders. The Journal of Creative Behaviour, 26 (3), pp. 165-171.

George, K.M. (2005). Creative thinking. In, C.G.Venkatesha Murthy and A.V. Govinda Rao. Life skills education tainting package: Part A Training Modules. Mysore: Regional Institute of Education.

Guilford, J.P. (1966). Creativity: Yesterday, today and tomorrow. The Journal of Creative Behaviour. p.13.

Gupta, A. K. (1979). Sex difference in creativity. Journal of Creative Behavior, 13 (4), pp. 269.

Habibollah., N., Rohani., A., Tengku Aizan, H., \& Jamaluddin, S. V., Mallan, K. (2008). Gender differences in creative perceptions of undergraduate students. Journal of Applied Sciences, (In Press).

Haddon, F. A. \& Lytton, H. (1968). Teaching approach and the development of divergent thinking abilities in primary schools. British Journal of Educational Psychology, 38, 171180.

Haddon, F. A., and Lytton, H. (1968). Teaching approach and the development of divergent thinking abilities in primary schools. British Journal of Educational Psychology, pp. 38, 171-80.

Kogan, M. (1974).Creativity and sex differences. The Journal of Creative Behaviour, 8 (1). pp. $1-14$.

Kusum, M.G.(2005).Creative thinking. In, C.G. Venkatesha Murthy and A.V.GFovinda Rao. Life skills education training package: Part A Training Modules. Mysore:Regional Institute of Education.

Laidra, K., Pullmann, H. \& Allik, J. (2007). Personality and intelligence as predictors of academic achievement: A cross-sectional study from elementary to secondary school. Journal of Personality and Individual Differences, 42, 441-451.

Nayana, T.S. (1981). Sex differences in creativity among adolescents in India. Psychological Abstracts.68, pp.7593.

O’Hara, L. A. \& Sternberg, R. J. (2001). It doesn't hurt to ask: Effects of instructions to be creative, practical, or analytical on essay writing performance and their interaction with students' thinking styles. Creativity Research Journal, 13,197-210.

Parns, S.J. (1972). Creativity unlocking human potential. New York: Creative Education Foundation.

Phathak, P. (1962). Experimental study of creativity and intelligence and school achievement. Psychological Studies, Mysore: 7, pp. 1-9. 


\section{Creativity among the Students of Jawahar Navodaya Vidyalayas and Kendriya Vidyalayas}

Plucker, J. A. \& Makel, M. C. (2010). Assessment of creativity. Cambridge handbook of creativity. New York: Cambridge University Press.(pp. 48-73).

Raina, M.K. (1969). A Study of Sex differences in creativity in India. The Journal of Creative Behavior, 3(2), pp. 111-114.

Rasool, G. (1977). A study of divergent thinking of school-going children. Creativity Newsletter, 6, (2), pp 23-26.

Rastogi, (1967) and Chatterji, (1970) cited in Agarwal, K. P. (1992). Development of Creativity in Indian Schools some related issues. New Delhi: Concept Published Company, pp. 4445.

Renuka. (2003). Emotional intelligence and creativity of school students. Indian Journal of Psychological Research, 2, pp.2-10.

Richmond, B. O. (1971). Creative and Cognitive abilities of White and Negro children. Journal of Negro Education, 40 (2), pp. 111-116.

Roy, J. (2008). Elementary teacher perceptions of teaching practices that foster creative thinking in students. Inquiry, 14, pp.75-94.

Runco, M. A. \& Albert, R. S. (1986). The threshold theory regarding creativity and intelligence: An empirical test with gifted and non-gifted children. Creative Child and Adult Quarterly, 14, 212-218.

Russ, S. (2003). Creativity research: Whither thou goest. Creativity Research Journal, 15, 143145.

Saima, S. (2011). A comparative study of creativity among boys and girls of class VII. Indian Educational Review, 49, (2), p.6.

Sarah. H. (2013). Collective engagement in creative tasks: The role of evaluation in the creative process in groups. Administrative Science Quarterly, 58, 346-386.

Sehgal, K. (1978). School systems as related to creativity of students. The Progress of Education, 52, (10 \& 11), pp. 207-211.

Sharma,H.L.(2015).Creativity Among High School Students Of Haryana In Relation To Socioeconomic Status And Type Of School,Indian stream research journal, 5,2, 2-8.

Singh, B. (1993). Measurement of creativity in young children, Ambala Cantt: The Associated Publishers (1st ed.), pp. 55-57, 114-116.

Singh, K. (1982). A study of creative thinking of high school students of Himachal Pradesh in relation to some cognitive and non cognitive variables. Survey of Research in Education, Vol. III.

Sultana. R. G. (1980) Streaming: a sociological perspective, Education (Malta), 3(3), 9-14.

Tanpraphat, A. (1976). A study of the relationship between creativity, academic achievement, scholastic aptitude, sex, and vocational interests of tenth grade Thai students. University of North Colorado, Greeley.

Tegano, D.W. \& Moran, J.D. (1989). Sex differences in the original thinking of preschool and elementary school children. Creativity Research Journal, 2 (1-2), pp. 102-110. 


\section{Creativity among the Students of Jawahar Navodaya Vidyalayas and Kendriya Vidyalayas}

Tharnmaprateep, V. (1976). A comparative study of creativity of Indian students (Baroda) and Thai students (Nakornsawan) of grade IX. Unpublished M.Ed. dissertation, Baroda: The M. S. University of Baroda.

Torrance, E.P. (1962). Guiding creative talent. Englewood Cliffs, N.J.: Prentice Hall.

Vohra, I. N. (1975). A study of non-verbal creativity in relation to socio-economic status, age, sex, medium of instruction and personality characteristics amongst the pupils of English and Gujarati Medium of'Bazm-E-Hidayat' primary school from Baroda city. Unpublished M.Ed. dissertation, M. S. University.

Warren, G.H., Luria. Z. (1972), “Evolutional set and creativity”, Perceptual Motor Skills, 1(2),pp.436-438.

Watkins, M. W. (1997). Discriminate and predictive validity of the WISC-III ACID profile among children with learning disabilities. Psychology in the Schools, 34 (4), 309-319.

How to cite this article: Kiran NC, Murthy V (2017), Creativity among the Students of Jawahar Navodaya Vidyalayas and Kendriya Vidyalayas, International Journal of Indian Psychology, Volume 4, Issue 2, No. 95, ISSN:2348-5396 (e), ISSN:2349-3429 (p), DIP:18.01.177/20170402, ISBN:978-1-365-84231-3 